\title{
Comparative study of single- and double-patch techniques for sinus venosus atrial septal defect with partial anomalous pulmonary venous connection
}

Anand P. Iyer, MCh, Krishnamanohar Somanrema, MCh, Sameet Pathak, MCh, Prashant Y. Manjunath, MS, Suraj Pradhan, MS, and Shyam Krishnan, MCh

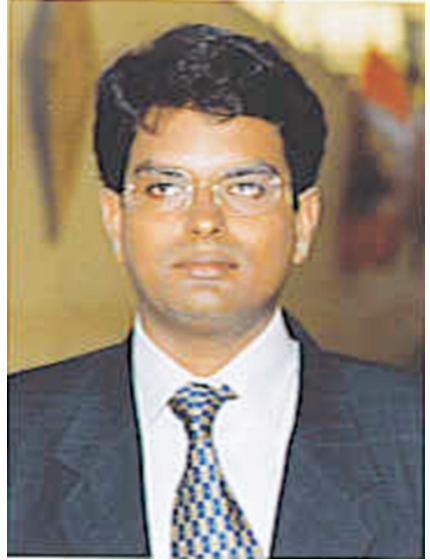

Dr Iyer

Objective: The correction of sinus venosus atrial septal defect with a partial anomalous pulmonary venous connection to the superior vena cava has been associated with obstruction to the venous return and sinus node dysfunction. We present our follow-up of 2 approaches of managing the lesion and compare their postoperative results.

Methods: Forty patients underwent operation between March 1999 and January 2005, of whom 37 patients (aged 3-50 years) are on follow-up. These patients were divided into 2 groups: single-patch repair (group A, 18 patients) and double-patch repair (group B, 19 patients). Echocardiography and electrocardiography were performed 7 days after surgery and during the subsequent follow-up.

Results: The mean duration of follow-up was 22.56 months. There were no postoperative deaths or residual defects. Six patients in group A and 2 patients in group $\mathrm{B}$ had turbulence and a significant superior vena cava-right atrium pressure gradient of more than $6 \mathrm{~mm} \mathrm{Hg}$. Nine patients in group A had a significant gradient causing turbulence across the right superior pulmonary vein at the level of the patch, whereas no patients in group B had turbulence across the pulmonary vein. Four patients in group A and no patients in group B had postoperative rhythm abnormalities on late follow-up. There was no other complication.

Conclusions: Partial anomalous pulmonary venous connection can be safely managed with multiple techniques with low morbidity. The double-patch technique is technically reproducible and offers better results in terms of superior vena cava narrowing and gradient across the pulmonary vein without any increase in complications.

From the Department of Pediatric Cardiac Surgery, Sree Chitra Tirunal Institute for Medical Sciences and Technology, Trivandrum, Kerala, India.

Received for publication March 28, 2006; revisions received June 22, 2006; accepted for publication Aug 7, 2006.

Reprint requests: Anand P. Iyer, MCh, Division of Pediatric and Congenital Heart Surgery, Sree Chitra Tirunal Institute for Medical Sciences and Technology, Trivandrum, Kerala, India-695 011 (E-mail: anandcvts@ hotmail.com).

J Thorac Cardiovasc Surg 2007;133:656-9

$0022-5223 / \$ 32.00$

Copyright $\odot 2007$ by The American Association for Thoracic Surgery

doi:10.1016/j.jtcvs.2006.08.076
$O$ inus venosus syndrome accounts for $10 \%$ of the patients presenting for surgery with an atrial septal defect (ASD). ${ }^{1}$ Sinus venosus syndrome comprises a sinus venosus ASD with a partial anomalous pulmonary venous connection (PAPVC) to the superior vena cava (SVC). Imperfect surgery in this condition may lead to sinus node dysfunction, residual shunt, and obstruction of the pulmonary veins or SVC. ${ }^{2-4}$ The goal of sinus venosus repair is to eliminate the intracardiac shunt without causing stenosis of the pulmonary veins or the SVC and without injuring the sinus node. Various surgical techniques have been adopted, for example, incisions across the cavoatrial junction, ${ }^{2,5}$ right atrium (RA) free wall muscle flaps ${ }^{6}$ and transection and relocation of the SVC to the RA appendage. ${ }^{7}$ Two commonly adopted techniques are the single-patch and double-patch repair. This study compared the postoperative results of both these approaches with respect to SVC narrowing, right superior pulmonary vein narrowing, residual ASD, and rhythm. 


$$
\begin{aligned}
& \text { Abbreviations and Acronyms } \\
& \begin{aligned}
\mathrm{ASD}= & \text { atrial septal defect } \\
\mathrm{PAPVC}= & \text { partial anomalous pulmonary venous } \\
& \text { connection } \\
\mathrm{RA} \quad= & \text { right atrium } \\
\mathrm{SVC} \quad= & \text { superior vena cava }
\end{aligned}
\end{aligned}
$$

\section{Materials and Methods}

Between March 1999 and January 2005, 40 patients underwent repair for sinus venosus ASD with PAPVC to the SVC, of whom 37 are on follow-up. These patients were divided into 2 groups: single-patch repair (group A, 18 patients) and double-patch repair (group B, 19 patients). Permission was obtained from the patients, hospital committee, and institutional review board. Both groups had similar preoperative anatomy with the right upper and middle pulmonary veins draining into the SVC just above and at the SVC-RA junction. The pulmonary veins draining high up in the SVC were excluded. The mean follow-up was 22.5 months. Patients' ages ranged from 3 to 50 years (mean: 15.1 years). The age range was 6 to 41 years in group A and 3 to 50 years in group B. The weight ranged from 15 to $68 \mathrm{~kg}$ in group A and 11 to $72 \mathrm{~kg}$ in group B. Twenty-eight of the 37 patients (75.6\%) were asymptomatic before surgery, whereas the remaining 9 patients demonstrated easy fatigability, chest pain, or reduced exercise tolerance. All of the symptomatic patients were aged more than 40 years. Preoperative echocardiography revealed a pulmonary hypertension of more than $30 \mathrm{~mm} \mathrm{Hg}$ in 7 patients. Documented arrhythmias were absent before surgery in all patients. A right bundle-branch block pattern was present in 10 patients (27\%). None of the patients underwent angiography. Follow-up included physical examination, 12-lead electrocardiography, and serial transthoracic echocardiography as part of the postoperative protocol. Color Doppler was used to assess the venous structures.

\section{Operative Technique}

In all patients, the SVC was cannulated above the anomalous venous drainage, and a curved cannula was used for the inferior vena cava. The surgery was performed under mild hypothermia and cardioplegic arrest. Eighteen patients (group A) underwent a single-patch technique in which a pericardial patch was used to close the ASD and reroute the anomalous pulmonary vein or veins into the left atrium, and the SVC was closed primarily. Nineteen patients underwent a double-patch technique in which a pericardial patch was used to enlarge the SVC (Figures 1 and 2), thereby providing an unimpaired drainage to the SVC and pulmonary veins (Figure 3). The ASD was not restrictive in any of these patients, and none had left SVC. Intraoperative transesophageal echocardiography was not used in any of the patients, and no patients required intraoperative revision.

\section{Results}

The mean duration of follow-up was 22.56 months. There were no early or late postoperative deaths. There were no residual defects in any of patients. Six patients in group A and 2 patients in group B had a significant SVC-RA pres-

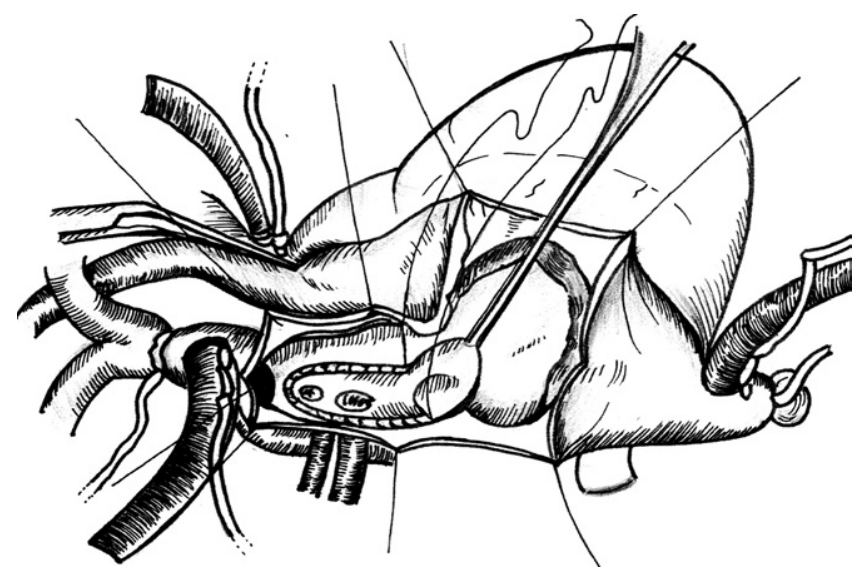

Figure 1. Pericardial patch closure of the atrial septal defect and rerouting of the anomalous pulmonary veins into the left atrium.

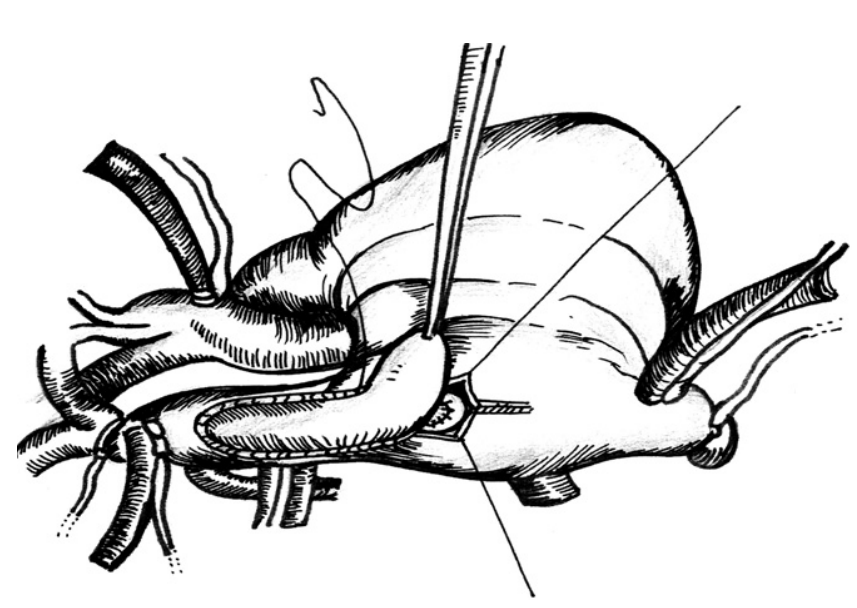

Figure 2. Pericardial patch enlargement of the superior vena cava with a second pericardial patch.

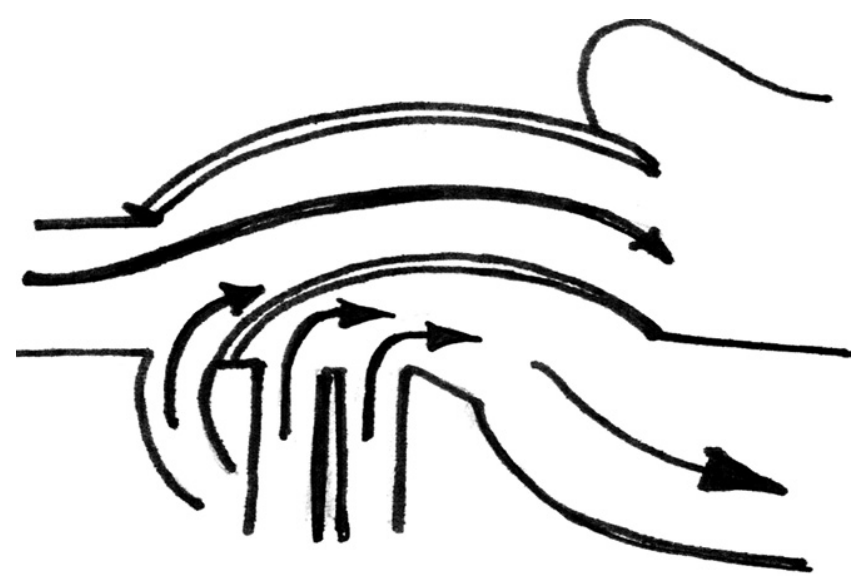

Figure 3. Diagrammatic representation of the double patch technique. 
sure gradient of more than $6 \mathrm{~mm} \mathrm{Hg}$ causing turbulence $(P=.005)$. The pressure gradients were present throughout the follow-up period. One patient in group A with a gradient of 13 had symptoms of SVC narrowing in the form of recent-onset headache, frequent episodes of giddiness, and a few dilated veins in the neck. Corrective surgery for this patient is under consideration. No cardiac catheterization was performed in any of these patients.

Nine patients in group A had a significant gradient causing turbulence across the right superior pulmonary vein at the level of the patch, whereas no patients in group B had turbulence across the pulmonary vein $(P=.0001)$. Of the 9 patients, 2 with a gradient of 9 and 8.4 had right-upper and middle-lobe haziness in repeated radiography. Both of these patients are asymptomatic and on follow-up.

Four patients in group A had postoperative junctional rhythm with intermittent sinus escapes. All of these patients are asymptomatic and on follow-up. None of the patients in group B had any rhythm disturbance. Four of the 7 patients who had elevated pulmonary artery pressure had reduction in pulmonary artery pressure postsurgery.

\section{Discussion}

The surgical management of sinus venosus ASD with PAPVC has evolved over the years, ranging from closure of the ASD and leaving or ligating the anomalous veins to total correction with rerouting of the anomalous veins to the left atrium. ${ }^{8,9}$

The common procedures include the single- or doublepatch technique, as shown by various reports. ${ }^{10-12}$ There have been speculations that compartmentalization of SVC with patch rerouting was followed by SVC obstruction. ${ }^{13,14}$ We showed that the double-patch method is superior to the single-patch method with regard to SVC narrowing. Both of the techniques were performed at the same time during the study period and adopted by the surgeons. This study was undertaken after SVC narrowing, and SVC syndrome developed in a few patients after the single-patch technique. There are significantly more patients who underwent operation without SVC augmentation $(P=.005)$ compared with patients who underwent a patch augmentation. Significant SVC gradient was noted as $6 \mathrm{~mm} \mathrm{Hg}$ by Trusler and colleagues. ${ }^{2}$ We have also observed turbulence in the SVC in the region of the patch, as visualized in Doppler, when the gradient is greater than $6 \mathrm{~mm}$.

None of the patients in group B had any gradient across the pulmonary vein caused by the patch, but 9 patients in group A have turbulence at that region in postoperative follow-up echocardiography $(P=.0001)$. This may be related to the fact that smaller patches are used in the single-patch method to prevent any redundancy of the patch, which may eventually cause SVC narrowing. The size of the patch is of utmost importance in this method because a smaller patch may cause pulmonary vein narrowing and a larger patch may contribute toward SVC narrowing. Some surgeons perform the single-patch method for PAPVC to the SVC-RA junction and a double-patch method for any other anomalous connection above the junction. ${ }^{12}$ All of our patients with the single patch had turbulence across the pulmonary veins and significant SVC gradient, including the patient with clinical and echocardiographic features of SVC stenosis who had PAPVC only to the SVC-RA junction. Turbulence across the pulmonary vein at the level of the patch developed in 4 patients in group A, 2 of whom had radiography findings of venous congestion. These patients are presently asymptomatic and on follow-up.

Rhythm disturbances are known complications of the surgery. We have encountered 4 patients with postoperative junctional rhythm, all of whom underwent the single-patch repair. This was the result of intraoperative damage to the sinoatrial node or the artery to the sinoatrial node. There were no rhythm abnormalities in the remaining patients in either group in the long-term follow-up. There are reports that an incision in the SVC or across the cavoatrial junction may cause sinus node dysfunction in follow-up even if there is no injury to the node or the artery because of fibrosis in that area. ${ }^{15}$ We have not encountered such events in longterm follow-up. DeLeon and colleagues ${ }^{16}$ observed rhythm abnormalities in only 2 of the 18 patients with cavoatrial incisions through the sinus node. Therefore, if the incision is properly planned and carefully sutured, the chance of rhythm abnormalities is less. The only risk is the varied course of the artery to the SA node, which may lie in the lateral aspect of the SVC-RA junction, but this risk persists for all the techniques except that of Gustafson and colleagues. ${ }^{7}$ This modification involves transection of the SVC with anastomosis to the RA appendage and has the disadvantage of a venous anastomosis with the possibility of acute thrombosis or subsequent stenosis. ${ }^{17}$ The transcaval repair involves an incision only in the SVC and is applicable for PAPVC to the SVC-RA junction, besides the patch should not be redundant whereby it can cause SVC obstruction. ${ }^{18}$ The double-patch technique to repair sinus venosus ASD with PAPVC is a safe, simple, and reproducible technique. It does not cause SVC or pulmonary venous obstruction and maintains normal sinus node function in the longterm follow-up.

\section{References}

1. Davia JE, Cheitlin MD, Bedynek JL. Sinus venosus atrial septal defects: analysis of 50 cases. Am Heart J. 1973;85:177-85.

2. Trusler GA, Kazenelson G, Freedom RM, Williams WG, Rowe RD Late results following repair of partial anomalous pulmonary venous connection with sinus venosus atrial septal defect. $J$ Thorac Cardiovasc Surg. 1980;79:776-81.

3. Friedli B, Gherin R, Davignon A, Fouron JC, Stanley P. Surgical treatment of partial anomalous pulmonary venous drainage. A long term follow up study. Circulation. 1972;45:159-70. 
4. Anderson PD, Glaser SP, Czarnecki S, Hopeman AR. Three unusual complications resulting from attempted repair of partial anomalous pulmonary venous drainage. Chest. 1976;69:384-7.

5. Kyger ER 3, Frazier OH, Cooley DA, Gillette PC, Reul GJ Jr, Sandiford FM. Sinus venosus atrial septal defect: early and late results following closure in 109 patients. Ann Thorac Surg. 1978;25:44-50.

6. Robicsek F, Daugherty HK, Cook JW, Serle JG. Sinus venosus type of atrial septal defect with partial anomalous pulmonary venous return. J Thorac Cardiovasc Surg. 1979;78:559-62.

7. Gustafson RA, Warden HE, Murray GF. Partial anomalous pulmonary venous connection to the superior venacava. Ann Thorac Surg. 1995; 60:S614-S7.

8. Kirklin JW, Ellis FH, Wood ED. Treatment of anomalous pulmonary venous connections in association with interatrial communications. Surgery. 1956;39:389-98.

9. Gustafson RA, Warden HE, Murray GF, Hill RC, Rozar GE. Partial anomalous pulmonary venous connection to the right side of the heart. J Thorac Cardiovasc Surg. 1989;98:861-8.

10. Ohmi M, Mohri H. A single pericardial patch technique for repair of partial anomalous pulmonary venous drainage associated with sinus venosus atrial septal defect. Ann Thorac Surg. 1988;46:360-1.
11. Kirklin/Barratt-Boyes. Cardiac Surgery. 3rd edition. Philadelphia: Churchill Livingstone; 2003. p. 715-52.

12. Backer CL, Mavroudis C. Paediatric Cardiac Surgery. 3rd edition. Philadelphia: Mosby; 2003. p. 283-97.

13. Kirklin JW, Ellis FH, Wood ED. Treatment of anomalous pulmonary venous connections in association with interatrial communications. Surgery. 1956;39:389-98.

14. Robicsek F, Daugherty HK, Cook JW, Selle JG. Sinus venosus type of atrial septal defect with partial anomalous pulmonary venous return. J Thorac Cardiovasc Surg. 1979;78:559-62.

15. Tung KSK, James TN, Effler DB, McCormack J. Injury of the sinus node in open-heart operations. J Thorac Cardiovasc Surg. 1967;53: 814-29.

16. DeLeon SY, Jenny EF, Ilbawi MN, Husayni TS, Quinones JA, Ow EP, et al. Surgical techniques in partial anomalous pulmonary veins to the superior vena cava. Ann Thorac Surg. 1993;55:1222-6.

17. Pathi V, Guererro R, MacArthur KJ, Jamieson MPG, Pollock JCS. Sinus venosus defect: single patch repair with caval enlargement. Ann Thorac Surg. 1995;59:1588-9.

18. Nicholson IA, Chard RB, Nunn GR, Cartmill TB. Transcaval repair of sinus venosus syndrome. J Thorac Cardiovasc Surg. 2000;119: $741-4$.

Access to The Journal of Thoracic and Cardiovascular Surgery Online is reserved for print subscribers!

Full-text access to The Journal of Thoracic and Cardiovascular Surgery Online is available for all print subscribers. To activate your individual online subscription, please visit The Journal of Thoracic and Cardiovascular Surgery Online, point your browser to http://www.mosby.com/jtcvs, follow the prompts to activate your online access, and follow the instructions. To activate your account, you will need your subscriber account number, which you can find on your mailing label (note: the number of digits in your subscriber account number varies from 6 to 10). See the example below in which the subscriber account number has been circled:

\section{Sample mailing label}

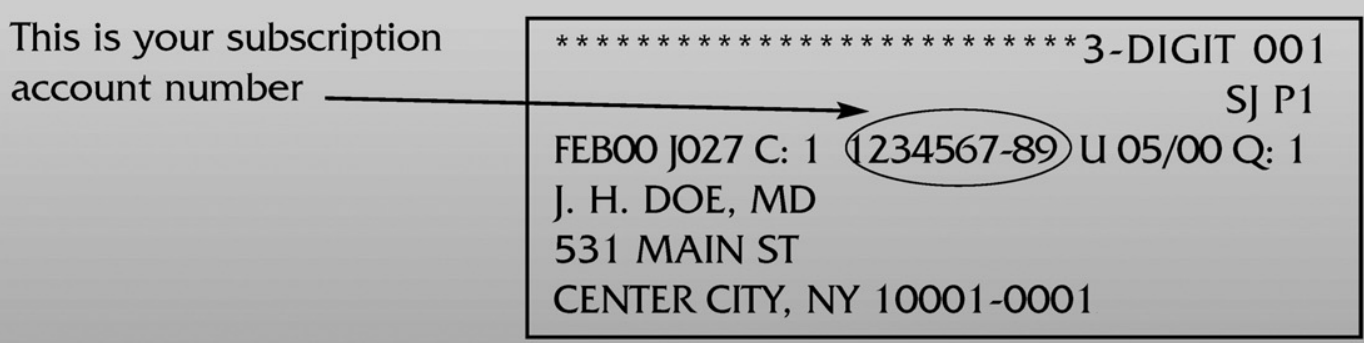

Personal subscriptions to The Journal of Thoracic and Cardiovascular Surgery Online are for individual use only and may not be transferred. Use of The Journal of Thoracic and Cardiovascular Surgery Online is subject to agreement to the terms and conditions as indicated online. 